\title{
Structural and functional changes in gap junctional intercellular communication in a rat model of overactive bladder syndrome induced by partial bladder outlet obstruction
}

\author{
FENGHAI ZHOU ${ }^{1}$, HAIYUAN LI ${ }^{2}$, CHUAN ZHOU ${ }^{3}$, HAIDI LV ${ }^{1}$, YULEI MA ${ }^{2}$, YANGMIN WANG ${ }^{1}$ and BO SONG ${ }^{4}$ \\ ${ }^{1}$ Department of Urology, Lanzhou General Hospital, Lanzhou Command, PLA, Lanzhou, Gansu 730050; \\ ${ }^{2}$ Department of Urology, The Second Clinical Medical College of Lanzhou University, Lanzhou, Gansu 730030; \\ ${ }^{3}$ Department of Urology, West China School of Medicine, Sichuan University, Chengdu, Sichuan 610000; \\ ${ }^{4}$ Department of Urology, Southwest Hospital, Third Military Medical University, \\ Chongqing 400038, P.R. China
}

Received November 21, 2014; Accepted December 22, 2015

DOI: $10.3892 / \mathrm{etm} .2016 .3246$

\begin{abstract}
The aim of the present study was to investigate the association between connexin (Cx)43 levels and alterations in gap junctional mediation of intercellular communication in overactive bladder syndrome $(\mathrm{OAB})$, and to examine the effects of connexin inhibitor on this condition. Adult female Wistar rats with $\mathrm{OAB}$ following partial bladder outlet obstruction (PBBO) (OAB group, $n=37$ ) and sham-operated rats (control group, $n=17$ ) were studied. The ultrastructure of the rat detrusor was observed by transmission electron microscopy and the protein expression levels of Cx43 were analyzed using western blot analysis. Furthermore, bladder detrusor cells in both groups were cultured and cells in the OAB group were randomly divided into ten groups. In nine of these groups, 18- $\beta$ glycyrrhetinic acid (18 $\beta-\mathrm{GA})$ was administered at various doses and durations. All groups were compared using fluorescence redistribution after photobleaching and a laser scanning confocal microscope. Cystometry demonstrated that gap junctions were an abundant mechanism among adjacent cells, and $\mathrm{Cx} 43$ protein expression levels were increased in the OAB group following 6 weeks of obstruction, as compared with the control group. Mean fluorescence recovery rates in the OAB group were significantly increased, as compared with the control group $(\mathrm{P}<0.01)$. Mean fluorescence recovery rates were noted following $18 \beta-\mathrm{GA}$ administration. These results suggested that upregulation of $\mathrm{Cx} 43$ induces structural and functional alterations in gap junctional intercellular
\end{abstract}

Correspondence to: Dr Fenghai Zhou, Department of Urology, Lanzhou General Hospital, Lanzhou Command, PLA, 333 Binhe South Road, Lanzhou, Gansu 730050, P.R. China E-mail: zhoufengh@163.com

Key words: overactive bladder syndrome, connexin 43, 18 $\beta$-GA, gap junctional intercellular communication communication following PBOO, and connexin inhibitors may be a novel therapeutic strategy for the clinical treatment of OAB.

\section{Introduction}

Overactive bladder syndrome (OAB), which is a highly prevalent clinical problem, is characterized by the key symptom of urgency, with or without urinary incontinence, and is usually associated with urinary frequency and nocturia (1,2). Partial bladder outlet obstruction (PBOO), which is predominantly caused by benign prostatic hyperplasia in elderly men, can induce bladder hypersensitivity and low bladder capacity (3), and is the most common cause of overactive bladder syndrome. Previous studies have demonstrated that myogenic bladder activity may be responsible for the pathophysiology of OAB in rats $(4,5)$ and humans $(5,6)$; however, the mechanisms are yet to be elucidated $(7,8)$. Therefore, investigations into potential therapeutic targets of the myogenic components of $\mathrm{OAB}$ in animal models ARE of clinical importance.

Connexin (Cx)43-mediated intercellular communication is a feature of bladder smooth muscle cells (BSMCs) (9). Cx43 is the principal protein component of the gap junctions and is responsible for the functional generation of gap junction channels. Increased coupling of BSMC via gap junctions is crucially involved in the physiological process of myogenic alterations that can directly impact $\mathrm{OAB}$ in the field of PBOO (10). Previous studies have demonstrated that upregulation of $\mathrm{Cx} 43$ associated with OAB is predominantly through alteration of the gap junctional intercellular communication system, as a result of BOO in rats and humans $(9,11)$.

Previous animal models of PBOO have demonstrated that myogenic changes are associated with decreased functional syncytia, increased Cx43 and gap junction generation (12), and changes in the transcriptional regulation of the connexin gene (10). There have been a number of previous studies investigating the structure and function of the underlying mechanisms of gap junctional intercellular communication in patients with $\mathrm{OAB}(9,13,14)$. In the present study, western 
blotting, fluorescence redistribution after photobleaching (FRAP) and laser scanning confocal microscopy (LSCM) were used to detect the expression levels of $\mathrm{Cx} 43$ protein and the functional alterations in gap junctional mediation of intercellular communication in OAB. As such, a potential mechanism of OAB pathogenesis was determined, which may provide a novel therapeutic mechanism for the clinical treatment of $\mathrm{OAB}$.

\section{Materials and methods}

Animals. A total of 62 Wistar female rats (age, 2 months; weight, 180-210 g) were purchased from the Experimental Animal Center of Lanzhou General Hospital (Gansu, China). Rats were randomly divided into two groups: Operation $(n=45)$ and sham operation $(n=17)$. During the present study, the rats received water and normal food ad libitum and survived $\geq 6$ weeks. All animals were sacrificed by intraperitoneal injection of $200 \mathrm{mg} / \mathrm{kg}$ phenobarbital (Shanghai Zhixin Chemical Co., Ltd., Shanghai, China), which was immediately followed by cystometry. The experimental protocol of the present study was approved by the Animal Research Ethics Committee of Lanzhou General Hospital. All surgical interventions and postoperative animal care were conducted in accordance with the Guide for the Care and Use of Laboratory Animals (National Research Council, Washington, DC, USA, 1996).

Procedure to establish a rat model of $P B O O$. In the operation group, each rat was anesthetized via intraperitoneal injection of $40 \mathrm{mg} / \mathrm{kg}$ phenobarbital (Shanghai Zhixin Chemical Co., Ltd., Shanghai, China). PBOO was induced as previously reported (15). A 25-G angioneedle sheath (Shanghai Pudong Jinhuan Medical Products Co., Ltd., Shanghai, China) was placed on top of the urethrovesical junction and ligated with 3-0 silk (Shanghai Pudong Jinhuan Medical Products Co., Ltd.) to create a PBOO. The sheath was subsequently removed and the incision was closed. In the sham operation group, a sham operation was performed under similar circumstances, with the exception of tying the ligature.

Cystometric investigations. Intravesical pressure was measured 6 weeks later following the partial ligation of the proximal urethra using a UD5000 (Dantec Dynamics, Skovlunde, Denmark). Rats were anesthetized via subcutaneous injection of $1.1 \mathrm{~g} / \mathrm{kg}$ urethane (Sigma-Aldrich, St. Louis, MO, USA). A total of 37 cases with overactive bladder were classified as the OAB group. A total of 17 rats underwent a sham operation, and were allocated as the control group. The bladder was catheterized through the bladder dome using polyethylene tubing connected to a Dantec Menuet urodynamic system (Dantec Dynamics, Ltd, Skovlunde, Denmark) via a three-way connector, in order to analyze infusion and pressure recordings. Cystometry was subsequently performed, warm saline $\left(37-38^{\circ} \mathrm{C}\right)$ was infused at a rate of $0.2 \mathrm{ml} / \mathrm{min}$, and the infusion was terminated when leakage of urine was detected around the tubing. The following urodynamic parameters were recorded using urodynamic apparatus (Dantec UD 5500 MK2; Dantec Dynamics): Intercontraction interval, micturition pressure, which is the maximum bladder pressure during micturition, and non-voiding contractions (NVC), which were evaluated three consecutive times in each animal in order to ascertain consistent bladder behavior. During bladder filling, NVC were measured in certain PBOO animals $(n=37)$ that had obvious NVCs prior to the onset of micturition and thus were defined as having $\mathrm{OAB}$, and were classified as the $\mathrm{OAB}$ group. A total of 17 rats underwent a sham operation as the control group.

Tissue specimen. Rat bladder tissue samples were harvested from both groups. The wet weight of bladder tissue samples in OAB group and control group were 630.8 \pm 71.25 and $120.0 \pm 6.45 \mathrm{mg}$, respectively $(\mathrm{P}<0.001)$. Serosa and mucosa were removed from the bladder under sterile conditions, and the detrusor tissues were immediately stored in liquid nitrogen.

Transmission electron microscopy. Bladder detrusor samples were fixed in $3 \%$ glutaraldehyde solution (Sigma-Aldrich) followed by 2\% osmium tetroxide (Department of Pathology, Lanzhou General Hospital, Lanzhou, China) in distilled water. Specimens $(\sim 1.0 \times 1.0 \times 1.0 \mathrm{~mm})$ were subsequently dehydrated using an alcohol gradient prior to infiltration and embedding with an Epon resin (Ted Pella, Inc., Redding, California, USA) gradient. The resin was polymerized at $60^{\circ} \mathrm{C}$ in an oven. Following this, the specimens were cut into ultrathin sections $(50 \mathrm{~nm})$ and placed on grids prior to staining with $3 \%$ uranyl acetate and lead citrate (both provided by the Department of Pathology, Lanzhou General Hospital). Sections were visualized using a CM10 electron microscope (Philips Medical Systems B.V, Eindhoven, The Netherlands) and images were captured (magnification, x6,000). The ultrastructural components of each sample were analyzed, particularly the presence of intercellular junctions, dense plaques and membrane caveolae.

Western blot analysis. Western blot analysis was used to verify the specificity of $\mathrm{Cx} 43$ antibody and to analyze the expression levels of $\mathrm{Cx} 43$ protein in the detrusor tissue. For protein extraction, the bladder smooth muscle (100 mg) was prepared in buffer ( $\mathrm{pH}$ 7.2) containing $1 \mathrm{mM}$ Tris- $\mathrm{HCl}$, $1 \mathrm{mM}$ DTT, $2 \%$ sodium dodecyl sulfate (SDS), and $0.1 \%$ bromchlorphenol blue (Sigma-Aldrich). Cells were dispersed by an VCX500 ultrasonic processor (Sonics \& Materials, Inc., Newton, CT, USA) and centrifuged at 1,000 rpm for $15 \mathrm{~min}$ at $4^{\circ} \mathrm{C}$, and the pellets obtained were incubated in homogenization buffer containing $1 \mathrm{mM}$ phenylmethylsulfonyl fluoride (Beyotime Institute of Biotechnology, Haimen, China) at $-20^{\circ} \mathrm{C}$. Following determination of the protein content via the Bradford assay (cat no. 5000201; Bio-Rad Laboratories, Hercules, CA, USA) using bovine serum albumin (Gibco; Thermo Fisher Scientific, Inc., Waltham, MA, USA) as standard, samples were diluted with 3X SDS gel-loading buffer (Sigma-Aldrich). For detection of $\mathrm{Cx} 43,40 \mu \mathrm{g}$ homogenate protein was loaded and separated by $12 \%$ SDS-polyacrylamide gel electrophoresis (Sigma-Aldrich). Proteins were subsequently transferred from unstained SDS gel to a polyvinylidene fluoride (PVDF) membrane (Merck Millipore, Darmstadt, Germany). PVDF was incubated in phosphate buffered saline (PBS; Wuhan 
Boster Biological Technology, Ltd., Wuhan, China) containing $5 \%$ skimmed milk (BD Diagnostics, Franklin Lakes, NJ, USA) and $0.1 \%$ Tween (Wuhan Boster Biological Technology, Ltd.) for $2 \mathrm{~h}$ non-fat dried milk at $37^{\circ} \mathrm{C}$ for $3 \mathrm{~h}$ in order to block non-specific binding. Blots were incubated for $4 \mathrm{~h}$ with goat anti-rat Cx43 polyclonal antibody (cat no. SAB2501246; 1:1,000; Sigma-Aldrich). Subsequent to incubation with the primary antibody, washing steps were performed. The PVDF membrane was washed three times with $0.1 \%$ Tween in cold PBS, and each wash lasted $15 \mathrm{~min}$. Following this, membranes were incubated for $2 \mathrm{~h}$ at $37^{\circ} \mathrm{C}$ with horseradish peroxidase-conjugated rabbit anti-goat immunoglobulin $\mathrm{G}$ (cat no. SAB3700303; 1:500; Sigma-Aldrich) was applied. Protein was detected using an enhanced chemiluminescence detection reagent (cat no. 32016; Pierce Biotechnology, Inc., Rockford, IL, USA). Short exposure (3-8 sec) X-ray film (Tianjin Media Imaging Materials Co., Ltd., Tianjin, China) was used for densitometric analysis. Cx43 protein expression levels were was estimated by measuring the relative optical density of the bands.

Cell culture. Primary cell cultures were produced from bladder specimens from the rat model of PBOO and normal rat bladder. Fresh bladder tissues were excised under sterile conditions and rinsed in sterile saline. Following removal of the serosa and mucosa, $\sim 0.5 \times 0.5 \times 0.5-\mathrm{mm}$ small tissue fragments were digested with $1 \mathrm{ml}$ collagenase $(0.125 \%$; Sigma-Aldrich) at $4^{\circ} \mathrm{C}$ for $12 \mathrm{~h}$. Subsequently, cells were cultured in Dulbecco's Modified Eagle's Medium (Hyclone; GE Healthcare Life Sciences, Logan, UT, USA) supplemented with $15 \%$ fetal bovine serum (Gibco) and $100 \mathrm{U} / \mathrm{ml}$ streptomycin and penicillin solution (Lanzhou General Hospital) in a 6-well Corning Costar cell culture plate (Sigma-Aldrich) coating with cover glasses (20x20 mm; provided by the Department of Pathology, Lanzhou General Hospital). Cell density was $5 \times 10^{5} / \mathrm{ml}$ at $37^{\circ} \mathrm{C}$ in an atmosphere containing $5 \% \mathrm{CO}_{2}$. One cover glass containing cultured cells was considered as a sample.

Administration of 18-beta glycyrrhetinic acid (18 $\beta$-GA) in the OAB group. $18 \beta$-GA (Sigma-Aldrich) was used to inhibit cell-cell communication in the OAB group. Detrusor smooth muscle cells in the OAB group were divided into 10 groups. Four groups were administered 10, 20, 40, 80 and $160 \mu \mathrm{mol} / 118 \beta-\mathrm{GA}$, respectively, for $2 \mathrm{~h}$. According to the result of a preliminary experiment performed for the present study that revealed that $40 \mu \mathrm{mol} / 118 \beta-\mathrm{GA}$ induced a stabilizing inhibitory effect, the remaining five groups were administered $40 \mu \mathrm{mol} / 1 \mathrm{1} \beta \beta-\mathrm{GA}$ for $30 \mathrm{~min}$ and 1, 2, 3 and $4 \mathrm{~h}$, respectively. Subsequent to the administration of $18 \beta-\mathrm{GA}$, the inhibitory efficacy on the increased detrusor excitability induced by the changes in cell-cell communication was evaluated by the mean fluorescence recovery rates.

Carboxyfluorescein diacetate (CFDA) loading. The aforementioned cultured detrusor cells (density, $5 \times 10^{5} / \mathrm{ml}$ ) were loaded with 6-CFDA fluorescent dye (Molecular Probes; Thermo Fisher Scientific, Inc.). 6-CFDA was diluted to $10 \mu \mathrm{g} / \mathrm{ml}$ using a HEPES solution (Sigma-Aldrich) containing $\mathrm{Ca}^{2+}$ and $\mathrm{Mg}^{2+}$. Cultured cells at 70-80\% confluency were rinsed three to four times with PBS solution and subsequently incubated with $0.5-1.0 \mathrm{ml}$ 6-CFDA at $37^{\circ} \mathrm{C}$ in an atmosphere containing $5 \% \mathrm{CO}_{2}$ for $10-15 \mathrm{~min}$. Samples were rinsed two to three times with PBS solution, and stored in small volumes of the culture solutions at $37^{\circ} \mathrm{C}$ in an atmosphere containing $5 \% \mathrm{CO}_{2}$ for further processing.

LSCM. LSCM was performed using a Leica TCS for Windows NT (Leica Microsystems GmbH, Wetzlar, Germany), which facilitated the selection of regions of interest and unbleached adjacent cells, using an Image Browser (version 2.61; Leica Microsystems $\mathrm{GmbH}$ ). Mean fluorescence intensity was recorded at various scan times (Leica Microsystems $\mathrm{GmbH}$ ).

FRAP assay. Samples were loaded and gap junctional intercellular communication in the detrusor cells was detected using a Leica LCSM. Three types of cells were selected for fluorescence microscopy: i) Bleached cells, which were in contact with adjacent cells that required bleaching with the laser (Ar-iocn laser (488 nm; Leica Microsystems GmbH; ii) single cells, which were not in contact with other cells, but require bleaching with the laser; and iii) unbleached cells, which were in contact with adjacent cells but did not require bleaching with the laser. Since the bleached cells contained gap junction, they were designated as the experimental groups, whereas single cells were used as controls as they contained no gap junction. As is customary, fluorescence was subjected to bleaching, even in the absence of the laser; therefore, unbleached cells were selected for background adjustment. The three identified types of cells were scanned prior to bleaching. Following bleaching, fluorescence recovery rates were recorded for $4 \mathrm{~min}$. All FRAP procedures, which consisted of loading, washing, selecting, bleaching and scanning were completed within 30-40 min. In accordance with the manufacturer's protocol for the Leica TCS NT, the bleach/time series parameters were set as follows: Laser power, $500 \mathrm{MW}$; bleaching degree, 30-60\%; bleaching intensity, $100 \%$; bleaching time per point, $2.0 \mathrm{sec}$; scanning intensity, 20\%; scans prior to bleaching, 1; scans following bleaching, 9; total scans, 10; interval time, $30 \mathrm{sec}$; and detection of the bleached region, $4 \mathrm{~min}$. Cultured detrusor smooth muscle cells were examined following bleaching in order to analyze the rates of fluorescence recovery at the various time points. Mean fluorescence recovery rates were calculated using the following formula:

$$
\mathrm{K}_{\mathrm{t}}=\left(\mathrm{I}_{\mathrm{b}}-\mathrm{I}_{\mathrm{b} 0}\right) /\left(\mathrm{I}_{\mathrm{u}}-\mathrm{I}_{\mathrm{u} 0}\right) \times 100 \% .
$$

Where $I_{u}$ is the fluorescence intensity of the unbleached area; $I_{u 0}$ is the fluorescence intensity of the background; $I_{b}$ is the fluorescence intensity of the bleached area following fluorescence recovery; $\mathrm{I}_{\mathrm{b} 0}$ is the fluorescence intensity of the bleached area immediately following bleaching; and $\mathrm{K}_{\mathrm{t}}$ is the mean fluorescence recovery rates as a function of time.

Statistical analysis. Microsoft Excel (Microsoft Corporation, Redmond, WA, USA) was used to perform calculations on the original data, which was acquired using the Leica TCS NT microscope. Data were expressed as the mean \pm standard deviation and were analyzed using SPSS 19.0 for Windows (IBM SPSS, Armonk, NY, USA). P<0.05 was considered to indicate a statistically significant difference. 


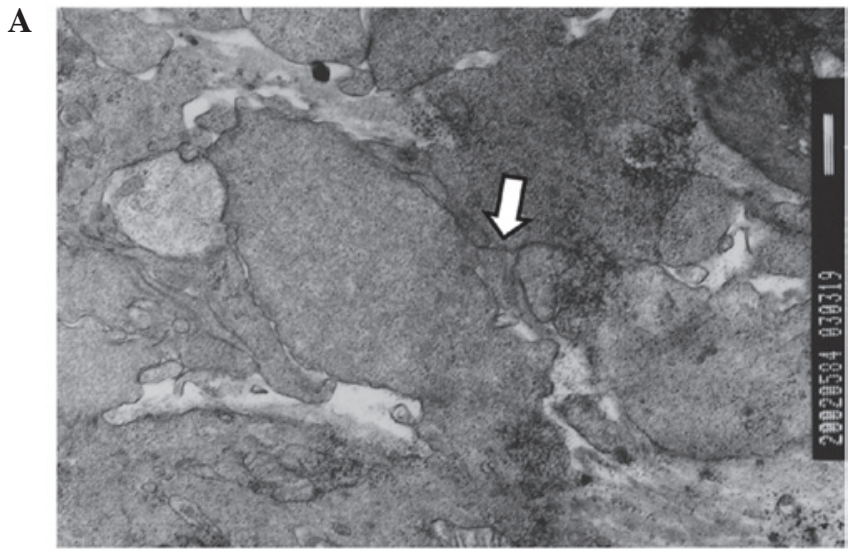

$\mathbf{B}$

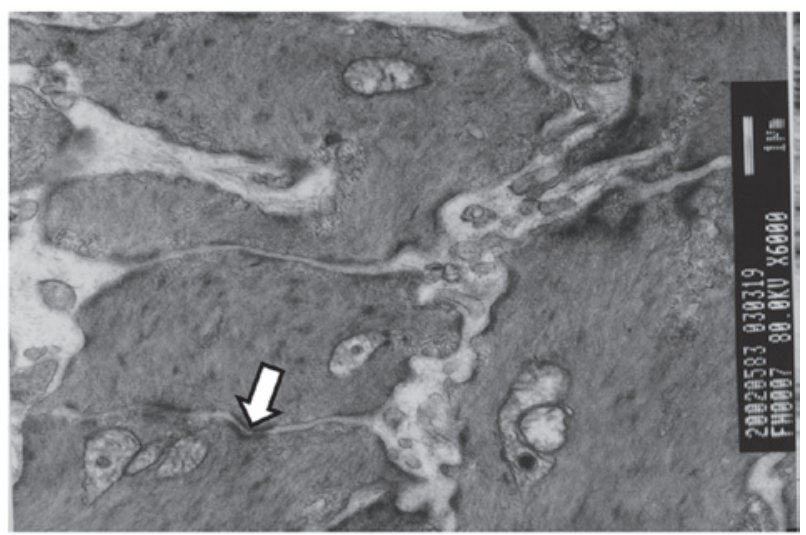

Figure 1. Observation with electron microscope (magnification, $x 6,000$ ). (A) Abundant gap junctions (arrowhead) were detected in the OAB group samples; whereas (B) Intermediate junction (arrowhead) were detected in the control samples. $\mathrm{OAB}$, overactive bladder syndrome.

\section{Results}

Transmission electron microscopy. The ultrathin sections demonstrated the characteristic multilayered growing pattern of cultured rat bladder detrusor cells, as detected via electron microscopy. Furthermore, abundant gap junctions were detected in the OAB group. Gap junctions were localized to protrusions and invaginations of the cell. Gap junctions were identified by their structure, between the cell processes of interstitial cells in the suburothelial zone (Fig. 1A). Intermediate junctions were detected in the control group samples, as laminated, symmetrical tight intercellular membrane junctions (Fig. 1B).

Expression levels of Cx43 protein in bladder detrusor. Western blot analysis demonstrated that $\mathrm{Cx} 43$ was the predominant protein expressed in the detrusor tissue of the OAB group. $\mathrm{Cx} 43$ protein expression levels were significantly increased in the OAB group, as compared with the control group $(\mathrm{P}<0.01)$. Further analyses demonstrated that these differences were accounted for by a 3 -fold increase in $\mathrm{Cx} 43$ protein expression levels in the OAB group (Fig. 2). These results demonstrated that $\mathrm{Cx} 43$ protein expression levels were significantly increased in rats with $\mathrm{PBOO}$-induced $\mathrm{OAB}$, as compared with the control group.

Alterations in the gap junctional intercellular communication of the detrusor smooth muscle cells. Cultured detrusor cells
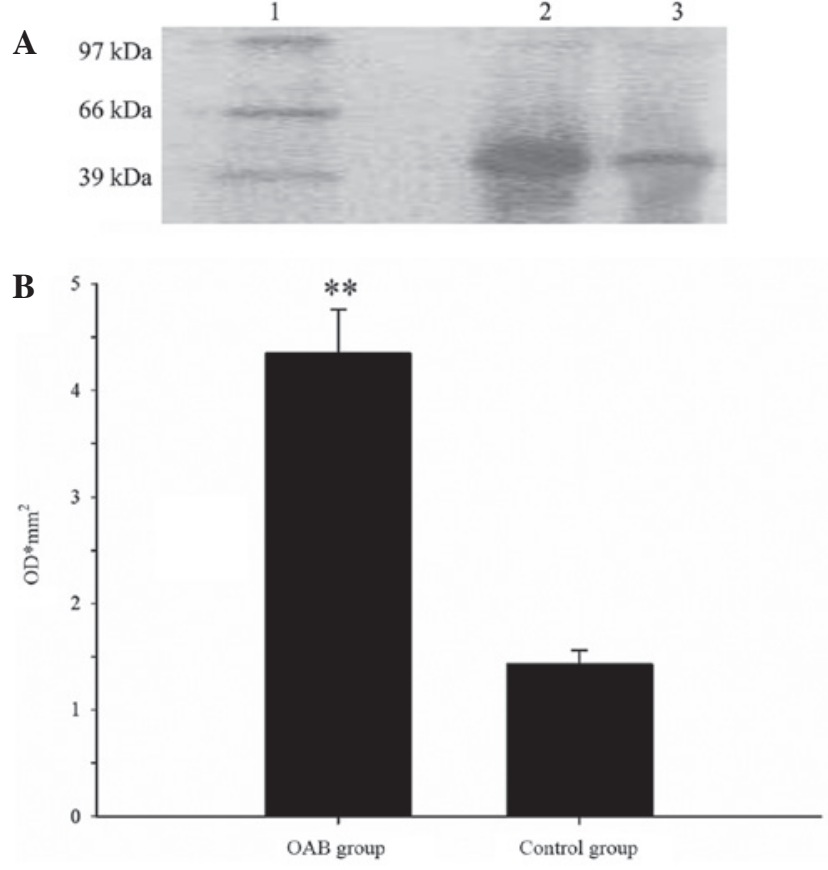

Figure 2. Western blot analysis of $\mathrm{Cx} 43$ expression levels in bladder detrusor. (A) Lane 1, LMw marker; lane 2, OAB group; and lane 3, control group. (B) $\mathrm{Cx} 43$ expression levels in bladder detrusor, as quantified by densitometry. ${ }^{* *} \mathrm{P}<0.01$ vs. the control group. $\mathrm{OAB}$, overactive bladder syndrome.

were loaded with 6-CFDA fluorescence probes and presented as a monolayer cell culture. FRAP was used to detect gap junctional intercellular communication between the cultured rat bladder detrusor cells in the OAB and control groups. Fluorescence recovery rates were analyzed in the cells prior to bleaching and at $0,1,2,3$ and 4 min following bleaching. The fluorescence intensity of cells in the OAB group gradually recovered across the various time points following bleaching, as compared with the initial dye distribution produced prior to bleaching (Fig. 3). The mean fluorescence recovery rates detected in the OAB group after 4 min were $35.79 \pm 0.84 \%$. By contrast, the mean fluorescence recovery of the bleached cells in the control groups was not obvious at the same time (Figs. 4 and 5). The mean fluorescence recovery rates detected in the control group after 4 min were $8.65 \pm 0.67 \%$. As compared with the control group, the mean fluorescence recovery rates of cells in the OAB group at 4 min were significantly higher $(\mathrm{P}<0.01)$ (Fig. 6). These results demonstrated that excitatory communication was more marked among adjacent cells in the OAB group, as compared with the control group.

Administration of $18 \beta-G A$ in the cells of the OAB group. The mean fluorescence recovery rates of cells 4 min after treatment with $10,20,40,80$ and $160 \mu \mathrm{mol} / 118 \beta$-GA were $20.19 \pm 1.83$, $12.81 \pm 0.14,7.09 \pm 0.08,6.24 \pm 0.11$ and $3.18 \pm 0.07 \%$, respectively. These mean fluorescence recovery rates were significantly decreased, as compared with the OAB group (42.40 $1.63 \%$; $\mathrm{P}<0.05)$ (Fig. 7). Treatment with $40 \mu \mathrm{mol} / 1$ 18 $\beta$-GA gap junction blocker suppressed the activity of PBOO bladders more effectively and at a steady rate compared with the other concentrations. However, no significant differences were detected in the mean fluorescence recovery rates of OAB cells treated with $40 \mu \mathrm{mol} / 1$ 18 $\beta-\mathrm{GA}$ at 2, 3 and $4 \mathrm{~h}$ (Fig. 8). 
A
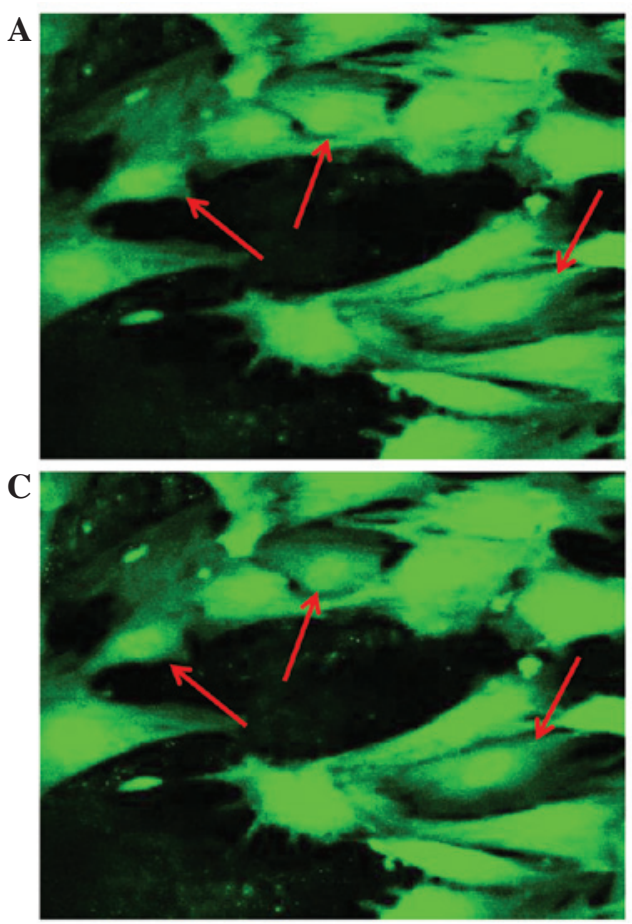
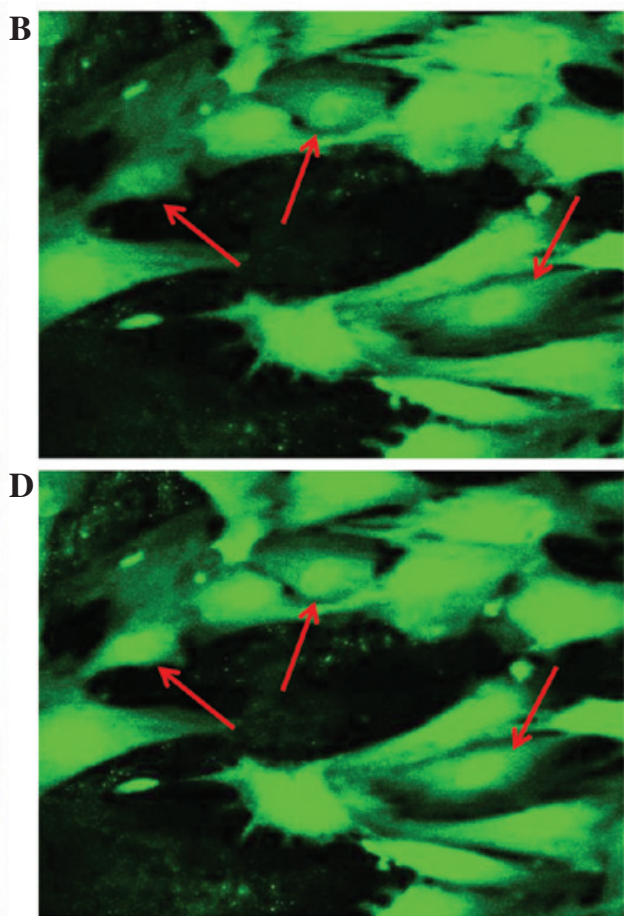

Figure 3. Gap junctional intercellular communication in detrusor smooth muscle cells in the overactive bladder syndrome group, as demonstrated by fluorescence redistribution after photobleaching. The arrows indicate the bleached cells. Images were captured (A) prior to bleaching and after bleaching at (B) 0 , (C) 2 and (D) 4 min.
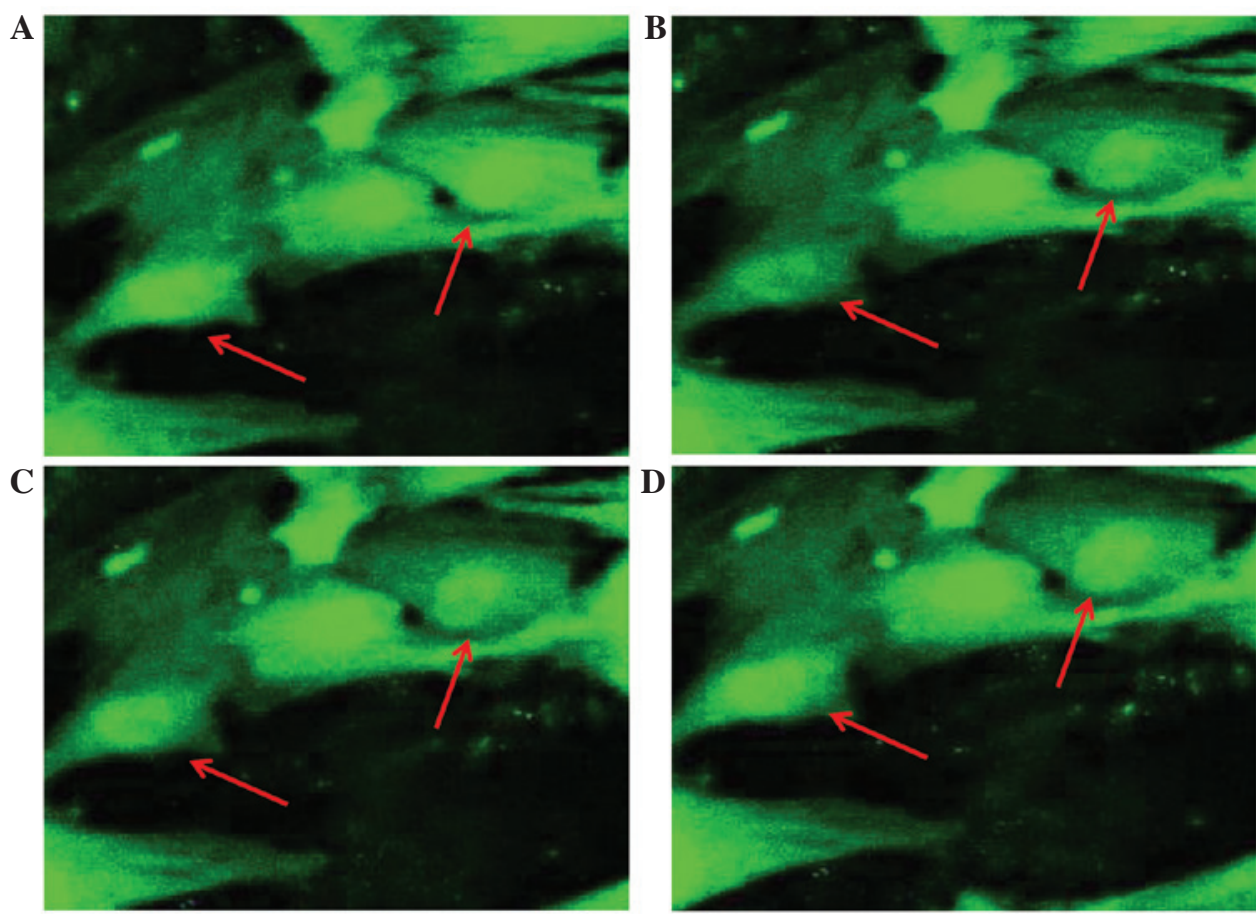

Figure 4. Gap junctions in detrusor cells of the control group, as demonstrated by fluorescence redistribution after photobleaching. The arrows indicate the bleached cells. Images were captured (A) prior to bleaching and after bleaching at (B) 0, (C) 2 and (D) 4 min.

\section{Discussion}

In the present study, gap junctional communication was investigated using a rat model of PBOO-induced OAB. The results demonstrated that $\mathrm{Cx} 43$ protein expression levels and intercellular gap junctions were increased, thereby altering contractile properties via the upregulation of cell-cell communication. Furthermore, the results of the present study demonstrated the $18 \beta$-GA gap junction blocker was able to reduce intercellular communication and may reduce the contractility of BSM. These results are consistent with previous studies $(15,16)$. 


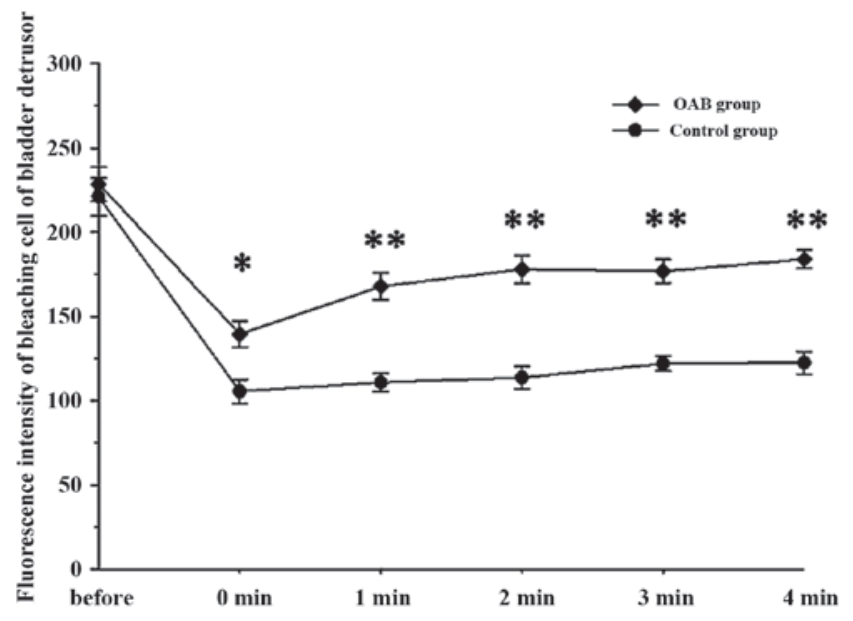

Figure 5. Fluorescence intensity of bleaching cell of bladder detrusor at various time points. Data are presented as the mean \pm standard deviation. ${ }^{*} \mathrm{P}<0.05$ vs. the control group, ${ }^{* *} \mathrm{P}<0.01$ vs. the control group. $\mathrm{OAB}$, overactive bladder syndrome.

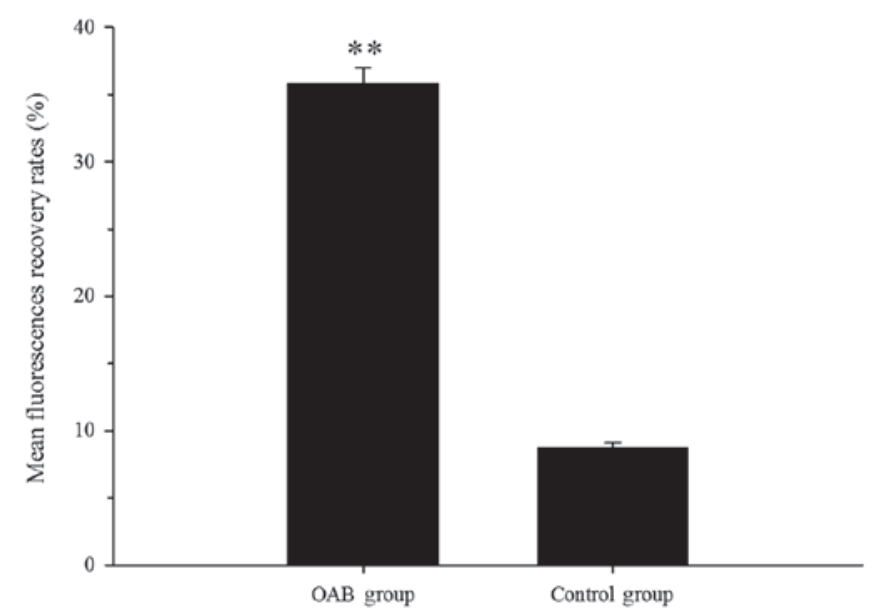

Figure 6. Mean fluorescence recovery rates of bladder detrusor cells at 4 min in the OAB and control groups. Data are presented as the mean \pm standard deviation. ${ }^{* *} \mathrm{P}<0.01$ vs. the control group. $\mathrm{OAB}$, overactive bladder syndrome.

Gap junctions, which are a characteristic of BSMCs, mediate intercellular communication by directly transmitting messages among adjacent cells. Gap junctions are specialized structures present in the plasma membranes of the majority of cell types which form aqueous channels to connect the cytoplasm of adjacent cells in order to facilitate the direct exchange of cytoplasmic components, without the interference of extracellular elements $(8,15)$. Gap junctions bridge the intervening extracellular space via the docking of two hemichannels which are contributed by each adjacent cell. Each hemichannel is an oligomer of six connexins molecules and several or thousands pairs of connexins constitute gap junctional plaques $(17,18)$. The quantity of gap junctional plaques is associated with gap junction intercellular communication (19). Gap junctions are specialized intercellular channels that facilitate the passage of small molecules, ions and metabolites $<1 \mathrm{kDa}$ through their low-resistance intercellular pores (20); therefore, gap junctions are capable of strengthening direct intercellular electrical and metabolic coupling $(21,22)$. Previous studies

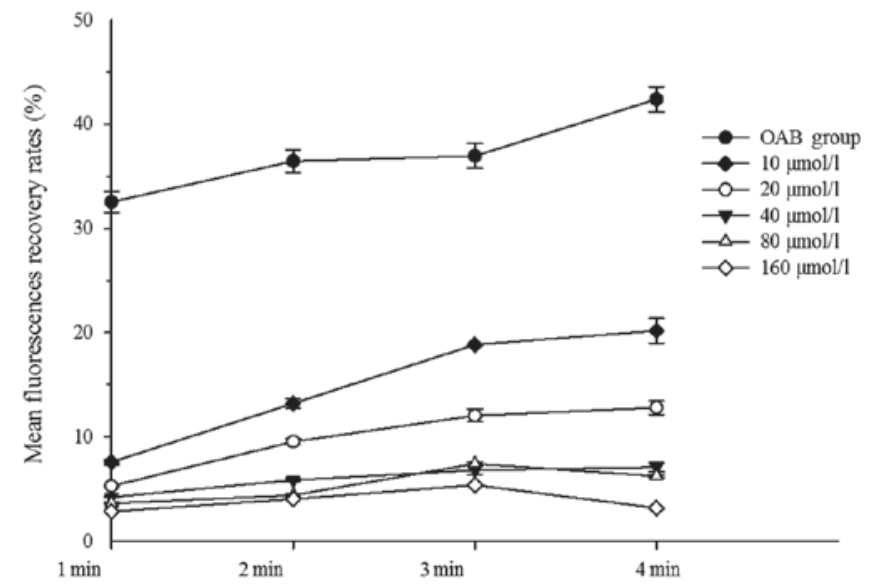

Figure 7. Mean fluorescence recovery rates in the OAB group in the presence of $18 \beta-\mathrm{GA}$ at various concentrations. Data are presented as the mean \pm standard deviation. $\mathrm{P}<0.01$ for $18 \beta-\mathrm{GA}$ at $10 \mu \mathrm{mol} / 1$ at 1 and $2 \mathrm{~min}$ vs. the corresponding $\mathrm{OAB}$ group; $\mathrm{P}<0.05$ for $18 \beta-\mathrm{GA}$ at $10 \mu \mathrm{mol} / \mathrm{l}$ at 3 and $4 \mathrm{~min}$ vs. the corresponding $\mathrm{OAB}$ group; $\mathrm{P}<0.01$ for $18 \beta-\mathrm{GA}$ at $20,40,80$ and $160 \mu \mathrm{mol} / 1$ at all time points vs. the corresponding OAB group. OAB, overactive bladder syndrome.

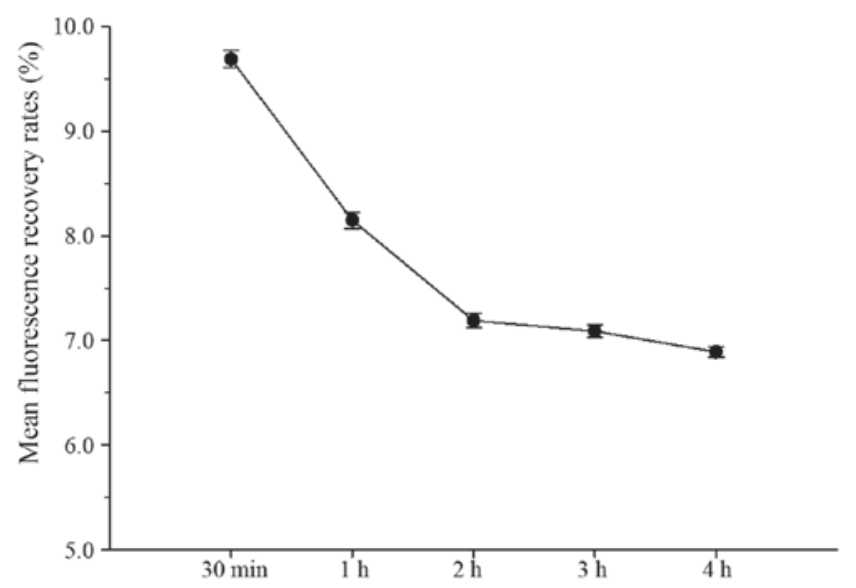

Figure 8. Mean fluorescence recovery rates $(4 \mathrm{~min})$ of cells in the OAB and control groups in the presence of the same $18 \beta-\mathrm{GA}$ concentration $(40 \mu \mathrm{mol} / \mathrm{l})$ at various time points. Data are presented as the mean \pm standard deviation. $\mathrm{OAB}$, overactive bladder syndrome.

have demonstrated that gap junction-mediated intercellular communication is a key mechanism in various physiologic processes, including the buffering of cytoplasmic ions, control of cellular growth and differentiation, and the coordination of smooth muscle contraction $(15,16,23)$. However, it has also been demonstrated that if $\mathrm{Cx} 43$ expression levels are reduced or the mechanism for contract coupling is lacking, the detrusor cannot produce a unified contraction (16).

Gap junctional intercellular communication is essential for bladder tissue functions and development (24). However, it has been demonstrated that the upregulation of $\mathrm{Cx} 43$ may be a predominant cause of myogenic alterations in $\mathrm{OAB}$, as demonstrated in short-term cultured BSMCs (9) and experimental animal studies $(11,16)$. Hashitani et al $(25)$ demonstrated the origin and propagation of spontaneous excitation in the smooth muscle of guinea-pig urinary bladder. In addition, immunohistochemical analysis of $\mathrm{Cx} 43$ 
demonstrated abundant punctate staining on the smooth muscle cell membranes (25). Furthermore, Miyazato et al (11) demonstrated that connexin 43 mRNA and protein expression levels were markedly altered for 3 days to 4 weeks following rat PBOO. However, Asamoto et al (26) reported that Cx43 mRNA expression levels were barely detectable in normal rat bladder tissue. In the present study, the expression levels of $\mathrm{Cx} 43$ protein were demonstrated to be significantly higher in the OAB group, as compared with those in the control group. This result suggested that there are a large number of gap junctions in the OAB group following PBOO. Gap junction channels allow the passage of small molecules, ions and metabolites to facilitate adjacent cell membrane depolarization, and extensive intercellular electrical communication (27). Therefore, the present study hypothesizes that the excitatory communication among neighboring cells may be associated with the pathogenesis of $\mathrm{OAB}$, as a large number of gap junctions were observed among neighboring cells in the OAB group following PBOO. Furthermore, gap junction channels facilitate adjacent cell membrane depolarization, and extensive intercellular electrical communication. Thus, excitatory communication among neighboring cells is increased in the OAB group following $\mathrm{PBOO}$, which may be associated with the pathogenesis of $\mathrm{OAB}$.

Although a variety of technologies have been utilized to the investigate connexin-mediated intercellular communication, including scrape loading, microinjection and dye transfer assay (28), the mechanisms underlying the production and regulation of detrusor excitability are yet to be elucidated. In particular, the functional changes in gap junction-mediated intercellular communication in patients with OAB remain unknown. Elucidation of these functional changes is necessary in order to evaluate the morphological changes of gap junctions in the detrusor of patients with OAB.

In the present study, FRAP was used to accurately visualize the functional changes of gap junctional intercellular communication in BCMCs. In the present study, bleaching cells that contained gap junctions exhibited varying degrees of fluorescence recovery following bleaching, and the single cells, which did not contain no gap junctions, did not exhibit fluorescence recovery following bleaching. Mean fluorescence recovery rates of the detrusor smooth muscle cells in the OAB groups at 4 min were significantly increased, as compared with the control group. However, the mean fluorescence recovery rates of BSMCs were markedly reduced in the 18 $\beta$-GA groups, as compared with the control group. These results also showed that excitatory communication among the adjacent cells was more marked in the OAB group. These results suggested that excitation via gap junctional intercellular communication may be associated with the pathogenesis of OAB. Although multiple types of intercellular communication may be simultaneously observed and measured under the same magnification, this technique did not allow for the measurement of the passage of small molecules, ions and metabolites through the gap junctions.

$18 \beta-\mathrm{GA}$ is a gap junction blocker which acts via dephosphorylation pathways to inhibit connexins $(15,29)$. Previous studies investigating the inhibition of communication among adjacent detrusor cells have demonstrated the function of $18 \beta-G A(15,16,30)$. Kim et al (15) showed that
Cx43 expression levels were markedly downregulated in the urothelium and detrusor muscle of rats in the BOO group treated with $18 \beta-\mathrm{GA}$, as compared with the results obtained from the BOO group. Furthermore, Ekman et al (30) demonstrated that $18 \beta-$ GA modulated spontaneous contractions in the trigone, although the same was not detected in the bladder dome. In the present study, $18 \beta-$ GA markedly inhibited cell-to-cell fluorescence conduction in cultivated BSMCs, and induced concentration-dependent inhibition of adjacent cells connectivity in rat OAB cells. However, the mean fluorescence recovery rates of rat $\mathrm{OAB}$ cells treated with $18 \beta-\mathrm{GA}$ demonstrated time-independent inhibition of the connectivity of adjacent cells, which was inconsistent with the results of a previous study (16). The results of the present study suggested that the therapeutic effects of connexin inhibitors may be used to treat patients with $\mathrm{OAB}$.

OAB is predominantly caused by spontaneous bladder contraction during the filling phase of the micturition cycle, which is thought to be due to contractile activity in the bladder wall (31). Previous studies have hypothesized that the neurogenic alterations in bladder innervation or the myogenic activity of BSM are associated with the pathophysiology of OAB $(10,32)$. Furthermore, upregulation of $\mathrm{Cx} 43$ expression levels has previously been detected in overactive neurogenic detrusor (13), idiopathic detrusor overactivity (14) and experimental animal studies $(15,16)$. Negoro et al $(33)$ demonstrated that increased Cx43 expression was associated with nocturia and contributed to diurnal changes in bladder capacity, which may induce sleep disturbance due to micturition. Therefore, enhanced intercellular communication plays an important role in the development of OAB. Although the molecular mechanisms underlying the pathophysiology of myogenic bladder activity that is responsible for OAB (10) remain unclear, gap junction blockers may provide a novel therapeutic strategy for the clinical treatment of OAB.

The results of the present study demonstrated that functional alterations in gap junction-mediated intercellular communication in OAB may be regarded as one of the key mechanisms underlying $\mathrm{OAB}$ pathogenesis. These may help to demonstrate the feasibility of resisting intercellular excitatory communication as a therapeutic target for the treatment of patients with $\mathrm{OAB}$ in the future.

\section{Acknowledgements}

The present study was supported by the National Natural Science Foundation of China (grant no. 30271304).

\section{References}

1. Abrams P, Cardozo L, Fall M, Griffiths D, Rosier P, Ulmsten U, van Kerrebroeck P, Victor A and Wein A; Standardisation Sub-committee of the International Continence Society: The standardisation of terminology of lower urinary tract function: Report from the standardisation sub-committee of the international continence society. Neurourol Urodyn 21: 167-178, 2002.

2. Shen W, Li L, Song B, Li W, Zhou Z and Guo R: Platelet-derived growth factor-BB increases expression of connexin 43 in an extracellular-regulated protein kinase-dependent manner in bladder smooth muscle cells. Int J Urol 20: 123-130, 2013.

3. Negoro H, Kanematsu A, Imamura M, Kimura Y, Matsuoka R, Tanaka M, Tabata Y and Ogawa O: Regulation of connexin 43 by basic fibroblast growth factor in the bladder: Transcriptional and behavioral implications. J Urol 185: 2398-2404, 2011. 
4. Lee WC, Chuang YC, Chiang PH, Chien CT, Yu HJ and Wu CC: Pathophysiological studies of overactive bladder and bladder motor dysfunction in a rat model of metabolic syndrome. The J Urol 186: 318-325, 2011.

5. Darblade B, Behr-Roussel D, Oger S, Hieble JP, Lebret T, Gorny D, Benoit G, Alexandre L and Giuliano F: Effects of potassium channel modulators on human detrusor smooth muscle myogenic phasic contractile activity: Potential therapeutic targets for overactive bladder. Urology 68: 442-448, 2006

6. Chacko S, Cortes E, Drake MJ and Fry CH: Does altered myogenic activity contribute to OAB symptoms from detrusor overactivity? ICI-RS 2013. Neurourol Urodyn 33: 577-580, 2014

7. Andersson KE: Detrusor myocyte activity and afferent signaling. Neurourol Urodyn 29: 97-106, 2010.

8. Babaoglu M, Zumrutbas AE, Acar IC, Hatip FB, Kucukatay V, Eskicorapci $\mathrm{S}$ and Aybek Z: Gap junction expression and the effects of gap junction inhibitors in overactive bladder models: Does ovariectomy have a role? Int Urol Nephrol 45: 1001-1008, 2013.

9. Neuhaus J, Heinrich M, Schwalenberg T and Stolzenburg JU: TGF-beta1 inhibits $\mathrm{Cx} 43$ expression and formation of functional syncytia in cultured smooth muscle cells from human detrusor. Eur Urol 55: 491-497, 2009.

10. Imamura M, Sugino Y, Long X, Slivano OJ, Nishikawa N, Yoshimura N and Miano JM: Myocardin and microRNA-1 modulate bladder activity through connexin 43 expression during post-natal development. J Cell Physiol 228: 1819-1826, 2013.

11. Miyazato M, Sugaya K, Nishijima S, Kadekawa K, Machida N, Oshiro Y and Saito S: Changes of bladder activity and connexin 43-derived gap junctions after partial bladder-outlet obstruction in rats. Int Urol Nephrol 41: 815-821, 2009.

12. Imamura $M$, Negoro $H$, Kanematsu $A$, Yamamoto $S$, Kimura $Y$, Nagane K, Yamasaki T, Kanatani I, Ito N, Tabata Y and Ogawa O: Basic fibroblast growth factor causes urinary bladder overactivity through gap junction generation in the smooth muscle. Am J Physiol Renal Physiol 297: F46-F54, 2009.

13. Phé V, Behr-Roussel D, Oger-Roussel S, Rouprêt M, Chartier-Kastler E, Lebret T, Karsenty G, Compérat E, Camparo P and Giuliano F: Involvement of connexins 43 and 45 in functional mechanism of human detrusor overactivity in neurogenic bladder. Urology 81: 1108. e1-e6, 2013.

14. Kuhn A, Stadlmayr W, Monga A, Cameron I and Anthony F: A pilot study of Connexin 43 (Cx43) in human bladder tissue in patients with idiopathic detrusor overactivity. Eur J Obstet Gynecol Reprod Biol 141: 83-86, 2008.

15. Kim SJ, Park EY, Hwang TK and Kim JC: Therapeutic effects of connexin inhibitors on detrusor overactivity induced by bladder outlet obstruction in rats. Urology 78: 475.e1-e7, 2011.

16. Li L, Jiang C, Hao P, Li W, Song C and Song B: Changes of gap junctional cell-cell communication in overactive detrusor in rats. Am J Physiol Cell Physiol 293: C1627-C1635, 2007.

17. Lampe PD and Lau AF: Regulation of gap junctions by phosphorylation of connexins. Arch Biochem Biophys 384: 205-215, 2000 .
18. Matsuuchi L and Naus CC: Gap junction proteins on the move: Connexins, the cytoskeleton and migration. Biochim Biophys Acta 1828: 94-108, 2013.

19. Abascal F and Zardoya R: Evolutionary analyses of gap junction protein families. Biochim Biophys Acta 1828: 4-14, 2013

20. Miyazato M, Sugaya K, Nishijima S, Oda M and Ogawa Y: A gap junction blocker inhibits isolated whole bladder activity in normal rats and rats with partial bladder outlet obstruction. Biomed Res 27: 203-209, 2006.

21. Falk MM: Biosynthesis and structural composition of gap junction intercellular membrane channels. Eur J Cell Biol 79: $564-574,2000$

22. Nagaraja S, Kapela A and Tsoukias NM: Intercellular communication in the vascular wall: A modeling perspective. Microcirculation 19: 391-402, 2012.

23. Oyamada M, Takebe K and Oyamada Y: Regulation of connexin expression by transcription factors and epigenetic mechanisms. Biochim Biophys Acta 1828: 118-133, 2013.

24. Christ GJ, Venkateswarlu K, Day NS, Valcic M, Santizo C, Zhao W, Wang HZ, Persson K and Andersson KE: Intercellular communication and bladder function. Adv Exp Med Biol 539 (PtA): 239-254, 2003.

25. Hashitani H, Fukuta $H$, Takano $H$, Klemm MF and Suzuki $H$ Origin and propagation of spontaneous excitation in smooth muscle of the guinea-pig urinary bladder. J Physiol 530: 273-286, 2001.

26. Asamoto M, Takahashi S, Imaida K, Shirai T and Fukushima S: Increased gap junctional intercellular communication capacity and connexin 43 and 26 expression in rat bladder carcinogenesis. Carcinogenesis 15: 2163-2166, 1994.

27. Laird DW: Life cycle of connexins in health and disease. Biochem J 394: 527-543, 2006.

28. Sancho M, Triguero D and Garcia-Pascual A: Direct coupling through gap junctions is not involved in urethral neurotransmission. Am J Physiol Renal Physiol 300: F864-F872, 2011.

29. Santicioli P and Maggi CA: Effect of 18beta-glycyrrhetinic acid on electromechanical coupling in the guinea-pig renal pelvis and ureter. British journal of pharmacology 129: $163-169,2000$

30. Ekman M, Andersson KE and Arner A: Signal transduction pathways of muscarinic receptor mediated activation in the newborn and adult mouse urinary bladder. BJU Int 103: 90-97, 2009.

31. Akino H: Spontaneous contractile activity of the detrusor muscle and its role in the pathogenesis of overactive bladder syndrome. Low Urin Tract Symptoms 4 (Suppl 1): 42-47, 2012.

32. Yoshimura N: Lower urinary tract symptoms (LUTS) and bladder afferent activity. Neurourol Urodyn 26 (6 Suppl): S908-S913, 2007

33. Negoro H, Kanematsu A, Doi M, Suadicani SO, Matsuo M, Imamura M, Okinami T, Nishikawa N, Oura T, Matsui S, et al: Involvement of urinary bladder Connexin43 and the circadian clock in coordination of diurnal micturition rhythm. Nat Commun 3: 809, 2012. 